\title{
Histoplanimetrical Study on the Spatial Relationship of Distribution of Indigenous Bacteria with Mucosal Lymphatic Follicles in Alimentary Tract of Rat
}

\author{
Kenkichi YAMAMOTO ${ }^{1)}$, Wang-Mei QI ${ }^{1)}$, Yuh YOKOO ${ }^{2)}$, Hidenori MIYATA²), \\ Kankanam Gamage Sanath UDAYANGA ${ }^{2)}$, Junichi KAWANO ${ }^{2)}$, Toshifumi YOKOYAMA ${ }^{1)}$, \\ Nobuhiko HOSHI ${ }^{1)}$ and Hiroshi KITAGAWA ${ }^{1) *}$ \\ ${ }^{1)}$ Department of Bioresource and Agrobiosciences, Graduate School of Science and Technology and \\ ${ }^{2)}$ Department of Bioresource Science, Graduate School of Agricultural Science, Kobe University, Kobe 657-8501, Japan
}

(Received 10 November 2008/Accepted 15 January 2009)

ABSTRACT. The spatial relationship between the distribution of indigenous bacteria (IB) and the situation of mucosal lymphatic follicles (LF) is histoplanimetrically studied in the rat alimentary tract. From the oral cavity to the nonglandular part of the stomach, IB adhered to the corneal layer of the most luminal mucosa. In the glandular part of the stomach, IB adhered only to the most luminal mucosa but not in the gastric pits. In the small intestine, IB consistently adhered around the apices of both intestinal villi and the domes, and their amounts decreased toward their basal portions. No IB entered the intestinal crypts. In the large intestine, IB consistently adhered to the most luminal mucosa. Numerous IB were suspended in the intestinal crypts of both the cecum and the proximal colon, whereas there were no IB in the crypts of the distal colon and the rectum. When IB spread over the basal portions of the intestinal villi, IB with the same morphology were detected on the neighboring LF, whereas no bacteria were detected on the neighboring LF, when IB were located in the apical to middle portions of the intestinal villi. This close relationship between the distribution of IB and mucosal LF was also observed in the large intestine. These results suggest that the most luminal mucosae are a fundamental settlement site of IB throughout the alimentary tract and that the hyperproliferation of IB's colonies might be detected by neighboring LF in the rat intestine. KEY WORDS: alimentary tract, histology, lymphoid organ, microbiological monitoring, rat.

The microflora consists of $10^{14}$ bacteria of 400 different species that generate intense metabolic activity and play important physiologic roles in the adult human alimentary tract $[3,21]$. In general, the amount of bacteria in the alimentary tract increases toward the distal end, reaching up to $10^{12} / \mathrm{g}$ bacteria in feces $[10,15]$ during the transit time of the chyme, which is 4-6 hr in the small intestine and 54-56 hr in the large intestine of healthy human [9]. The large amount of bacteria in the chyme is thought to originate from the indigenous intestinal microflora on the alimentary mucosa. Indigenous bacteria live symbiotically and their composition is almost stable in the alimentary tract under physiological conditions [12]. Recently, the narrow apical portions of both the intestinal villi and the domes of mucosal lymphatic follicles (LF) have been speculated to be the constant adhering sites of indigenous bacteria in the rat jejunoileum [7, 16]. However, the adhesion sites of indigenous bacteria have not been histoplanimetrically demonstrated in the jejunoileum or in other alimentary portions of the rat.

The relationship between intestinal microflora and gutassociated lymphatic tissue (GALT) is reciprocal: i.e., the GALT plays a key role in forming intestinal microflora, although details of the mechanisms are still unclear [11, 30]. Indigenous bacteria in the alimentary tract have been considered to be regulated by the frequent replacement of

\footnotetext{
* Correspondence to: Kitagawa, H., Graduate School of Agricultural Science, Kobe University, Kobe 657-8501, Japan. e-mail: hkitagaw@kobe-u.ac.jp
}

epithelial cells and the secretion of antimicrobial substances such as transferrin, lysozyme, defensin and natural antibodies [4, 26]. However, the concrete mechanism by which bacterial proliferation is regulated in the alimentary tract has never been elucidated in vivo. Recently, the relationship between the proliferation of indigenous bacteria on the follicle-associated epithelium (FAE) and the differentiation of $\mathrm{M}$ cells in the FAE of the Peyer's patch have been clarified in the rat jejunoileum. This report speculates that the uptake of their bacteria by $\mathrm{M}$ cells might contribute to the regulation of the development of indigenous bacterial colonies in the rat jejunoileum [7]. However, the spatial relationship between the distribution of indigenous bacteria and the mucosal LF throughout the alimentary tract has never been demonstrated. In the present study, we histoplanimetrically investigate the spatial relationship between the distribution of mucosal LF and the expansion of bacterial colonies throughout the alimentary tract, in addition to the detection of fundamental settlement sites of indigenous bacteria.

\section{MATERIALS AND METHODS}

Animals: A total of 19 male Wistar rats aged 7 weeks (Japan SLC Inc., Hamamatsu, Japan) were maintained under conventional laboratory housing conditions. No pathogenic microorganisms were detected in the animal strain. The rats were permitted free access to water and food (Lab MR Stock; Nosan Corp., Yokohama, Japan). The animal facility was maintained under conditions of a $12 \mathrm{hr}$ 
light/dark cycle, at $21 \pm 1^{\circ} \mathrm{C}$ and $50-60 \%$ humidity. No signs of disorder were confirmed by clinical and pathological examinations in all animals. This experiment was approved by the Institutional Animal Care and Use Committee (Permission number: 17-04-05) and carried out according to the Kobe University Animal Experimentation Regulations.

Microbiological identification of microflora: Prior to histoplanimetry, the microbial identification of microflora was carried out on the mucosa from the oral cavity to the rectum. Briefly, 15 animals were killed by i.p. injection of overdose pentobarbital sodium (Dainippon Sumitomo Pharmaceuticals, Osaka, Japan). The entire alimentary tract was aseptically removed and segmented into 11 portions. Following longitudinal incision of each segment, the feces and mucus were thoroughly removed by repeatedly pressing it with aseptic soft paper. Then, the indigenous bacteria which adhered to the mucosal surfaces and resided in the deep spaces of the mucosa were collected by scraping with aseptic Q-tips. The bacteria, preserved in Seedtube (Eiken Chemical., Tokyo, Japan), were cultivated and the bacterial species were identified in the laboratories of the Chemotherapy Division, Mitsubishi Kagaku Bio-Clinical Laboratories (Tokyo, Japan) (Fig. 1).

Light microscopy: After cardiac exsanguination under anesthesia with i.p. injection of pentobarbital sodium (Dainippon Sumitomo Pharmaceuticals), the alimentary tract was gently removed, straightened, perfused slowly with cold Bouin's fixative, and cut into 6 segments: tongue, esophagus, stomach, small intestine, cecum and colon and rectum. Then, each segment was further cut into about $2 \mathrm{~cm}$ pieces, and immersion-fixed in the same fixative for $24 \mathrm{hr}$ at $4^{\circ} \mathrm{C}$. The tissue blocks were then dehydrated and embedded in paraffin. Each tissue block was sliced into $4-\mu \mathrm{m}$-thick sections along the longitudinal axis of the canal. In the case of the small and large intestine, the tissue block was sliced longitudinally through mesenteric to antimesenteric side. Paraffin sections were stained with hematoxylin and eosin.

Measurement of mucosal LF: The distribution of mucosal LF was investigated using an $20 \times$ objective lens under light microscope. The full (100\%) lengths of alimentary segments were defined as follows: the tongue from the tip to the root, esophagus from the origin to the cardiac opening, stomach from the cardiac opening to the pyloric opening through the greater curvature, small intestine from the pyloric opening to the ileal opening, cecum from the ileal opening to the cecocolic orifice through the apex of cecum, and colon and rectum from the cecocolic orifice to the end of rectum. The number of mucosal LF was counted in each $5 \%$ length of each alimentary segment. In the small and large intestine, the solitary and the aggregated mucosal LF were counted on the mesenteric side and the antimesenteric side on the longitudinally-sliced section, respectively.

Measurement of indigenous bacteria: The distributions of indigenous bacteria were measured using an oil-immersion $100 \times$ objective lens. Each alimentary segment was represented as $100 \%$, as described in "measurement of mucosal LF”. The length of each gastric pit in the stomach, each intestinal villus in the small intestine and each intestinal crypt in the large intestine was represented as $100 \%$. In each alimentary segment, the number of indigenous bacterial colonies was estimated, with the
Tongue

Esophagus

Stomach (non-Glandular)

Stomach (Glandular)

Duodenum

Jejunum

Ileum

Cecum

Colon (proximal)

Colon (distal)

Rectum

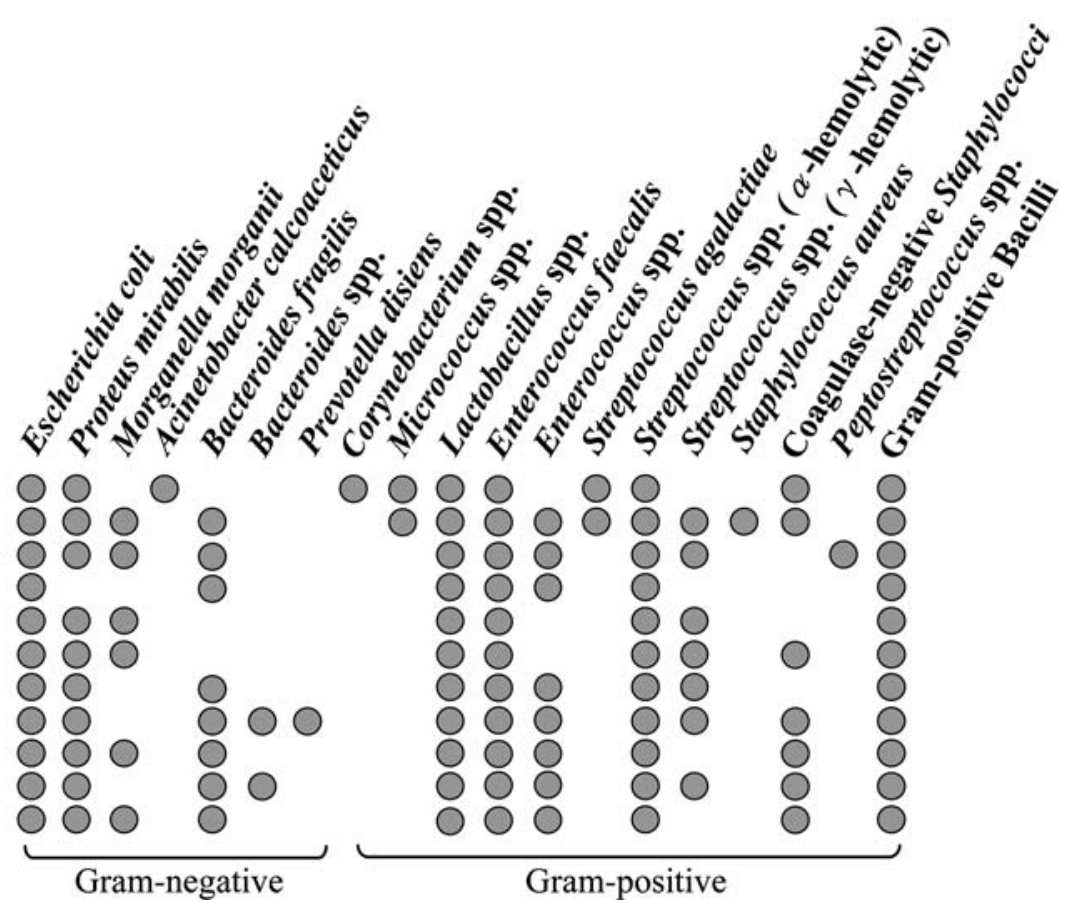

Fig. 1. The species of indigenous bacteria detected on the mucosa throughout the rat alimentary tract. $\mathbf{O}$, detected. 
existence of an indigenous bacterial colony in a rectangular area with sides constituting $1 \%$ of each segment length times $5 \%$ of the depth of crypt (height of intestinal villus), counting as 1 point.

\section{RESULTS}

Distribution of mucosal lymphatic follicles: No mucosal LF were detected in the mucosae of the tongue, esophagus and stomach. In the small intestine, the mucosal LF were more numerous on the antimesenteric than on the mesenteric side on the longitudinally-sliced section (Fig. 2a). The distribution pattern of Peyer's patches and their LF was similar to that of the solitary LF in the small intestine, though the total number of LF in aggregated LF was more numerous than that in solitary ones (Fig. 3a, b). The dome of LF was slightly low in comparison with the neighboring intestinal villi and was tightly covered with follicleassociated intestinal villi except for the narrow apical portion (Fig. 4a). In the cecum, the solitary LF were predominantly distributed in the mucosa, whereas the aggregated LF were limited to small numbers (Fig. 3c, d). In the colon and rectum, the mucosal LF were also more numerous on the antimesenteric than on the mesenteric side (Fig. 2b). Solitary LF were more widely distributed than the aggregated LF (Fig. 3e, f). Both the solitary and aggregated LF were sparse in the proximal colon. Each mucosal LF was located in the intestinal crypt in the large intestine (Fig. 4b).

Distribution of bacterial colonies: Indigenous bacteria observed on the mucosal epithelia in the alimentary tract were morphologically classified into 18 types: 15 bacilli forms (B1-B15) and 3 coccal forms (C1-C3) (Fig. 5). The predominant form was the bacilli form, whereas the coccal form was less common (Tab. 1). The correspondence between the results from morphological typing and those from the microbiological identification was failed to elucidate in this study.

In the tongue, type C3 bacteria adhered to the dorsal surfaces of filiform papillae exclusively, whereas no bacteria were detected at the ventral surfaces (Fig. 6a). In the esophagus, type C2 bacteria adhered to the corneal layer of the stratified squamous epithelium. Some bacteria invaded the superficial portion of the corneal layer. In the stomach, type B1, B2, B3, B7 and B11 bacteria adhered to the epithelium of the most luminal mucosa. More numerous bacteria resided in the nonglandular part than in the glandular part. In the nonglandular part, some bacteria also invaded in the superficial portion of the corneal layer (Fig. 6b). In the glandular part, a few indigenous bacteria sparsely adhered to the gastric surface epithelial cells of the most luminal mucosa, but did not invade the gastric pits.

In the small intestine, no difference was found in the bacterial distribution between the mesenteric and antimesenteric sides on the longitudinally-sliced sections. Almost all indigenous bacteria adhered around the apices of intestinal villi (Fig. 6c). The amount of indigenous bacteria in the intervillous spaces suddenly decreased toward the bases of intestinal villi (Fig. 7). In the areas where type B2, B4-B9, B12 and C1 bacteria colonized at the levels from the apical to basal portions of intestinal villi, the same type of indigenous bacteria also adhered to the FAE of the neighboring mucosal LF (Fig. 8a). In the area where type B1, B2, B6, B7, B13 and B14 bacteria colonized at the levels from in the apical to middle portions of intestinal villi, the same type of bacteria was never detected on the FAE of the neighboring mucosal LF (Fig. 8b). In the middle and basal portions of the intervillous spaces, most indigenous
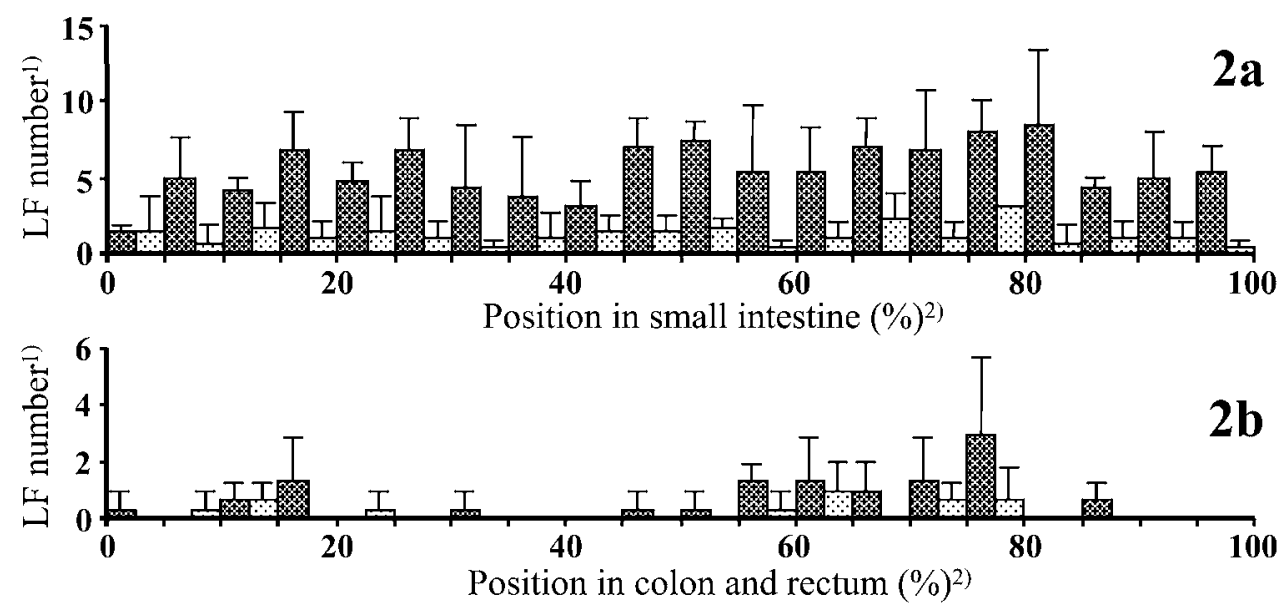

Fig. 2. The distribution of mucosal lymphatic follicles (LF) in the anti-mesenteric side (dark columns) and the mesenteric side (light columns) on the longitudinally-sliced sections of rat small intestine (a) and colon and rectum (b). 1) The number of mucosal LF is represented in each 5\% length. 2) The full (100\%) length of the small intestine is from the pyloric opening to the ileal opening, that of the colon and rectum is from cecocolic orifice to the end of the rectum. Each value represents a mean \pm SD. 

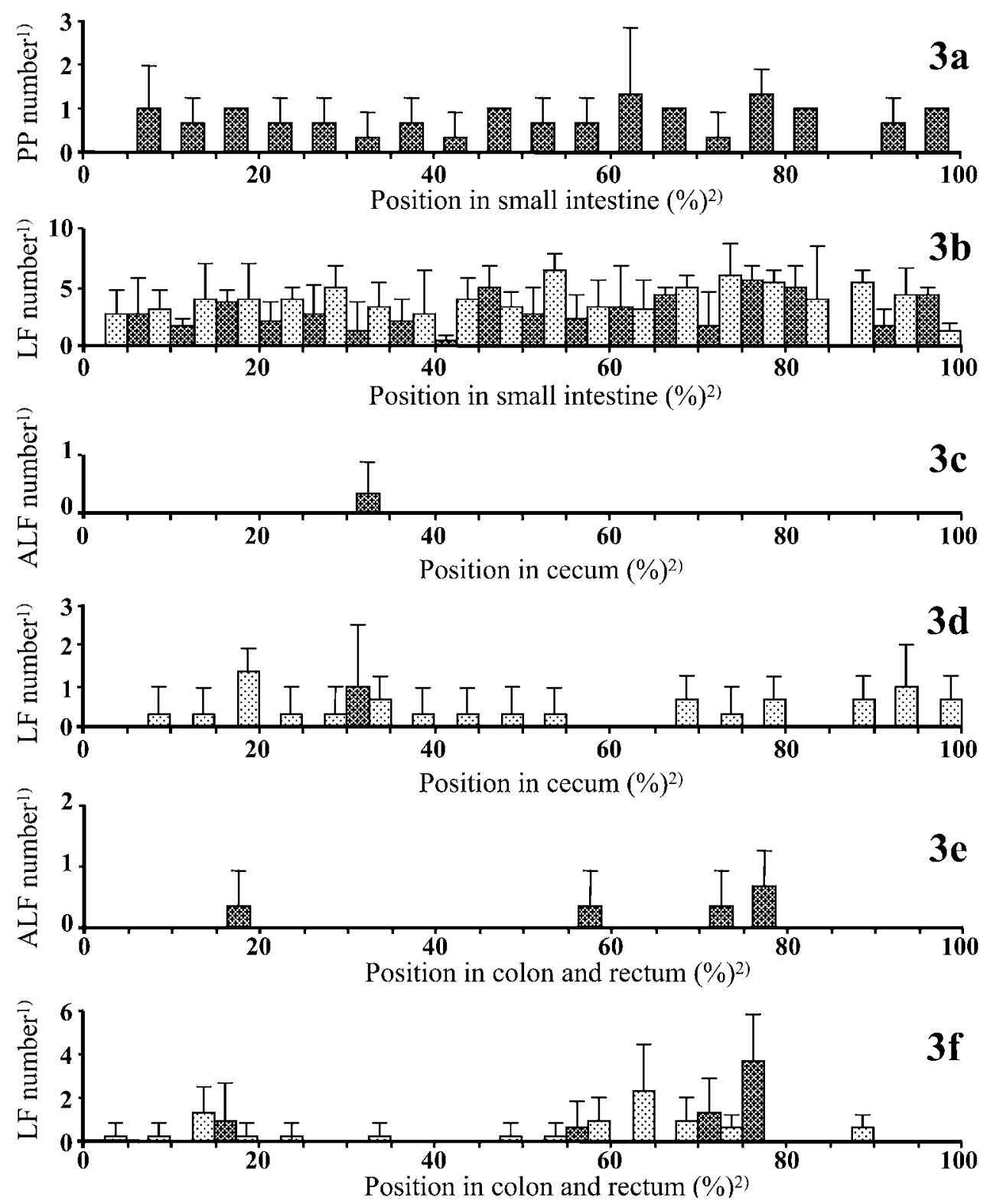

Fig. 3. The distribution of the Peyer's patches (a), and lymphatic follicles (LF) in Peyer's patches (dark columns) and the solitary LF (light columns) in small intestine (b). The distribution of aggregated LF (c) and LF in aggregated LF (dark columns) and the solitary LF (light columns) in cecum (d). The distribution of aggregated LF (e) and LF in aggregated LF (dark columns) and the solitary LF (light columns) (f) in the colon and rectum of rat. 1) Mean number ( \pm SD) of the LF is represented in each $5 \%$ length. 2) The full $(100 \%)$ length of the small intestine is from the pyloric opening to the ileal opening, that of the cecum is from the ileal opening to the cecocolic orifice through the apex of the cecum, and that of the colon and rectum from the cecocolic orifice to the end of the rectum.

bacteria did not adhere to the villous epithelium but were suspended in the mucus. No indigenous bacteria were detected in the intestinal crypts of the small intestine.

The types and amount of indigenous bacteria increased toward the distal small intestine. In addition, indigenous bacteria adhering to the mucosal LF also increased toward the distal small intestine (Fig. 9). No relationship was found between the distribution of mucosal LF and that of indigenous bacteria (Fig. 3b, 9).

In the cecum and the proximal $30 \%$ of the colon, a large amount of indigenous bacteria resided in the intestinal crypts, whereas the indigenous bacteria resided only in the most luminal mucosa in the distal $70 \%$ colon and rectum (Fig. 10). Indigenous bacteria consistently adhered to the 

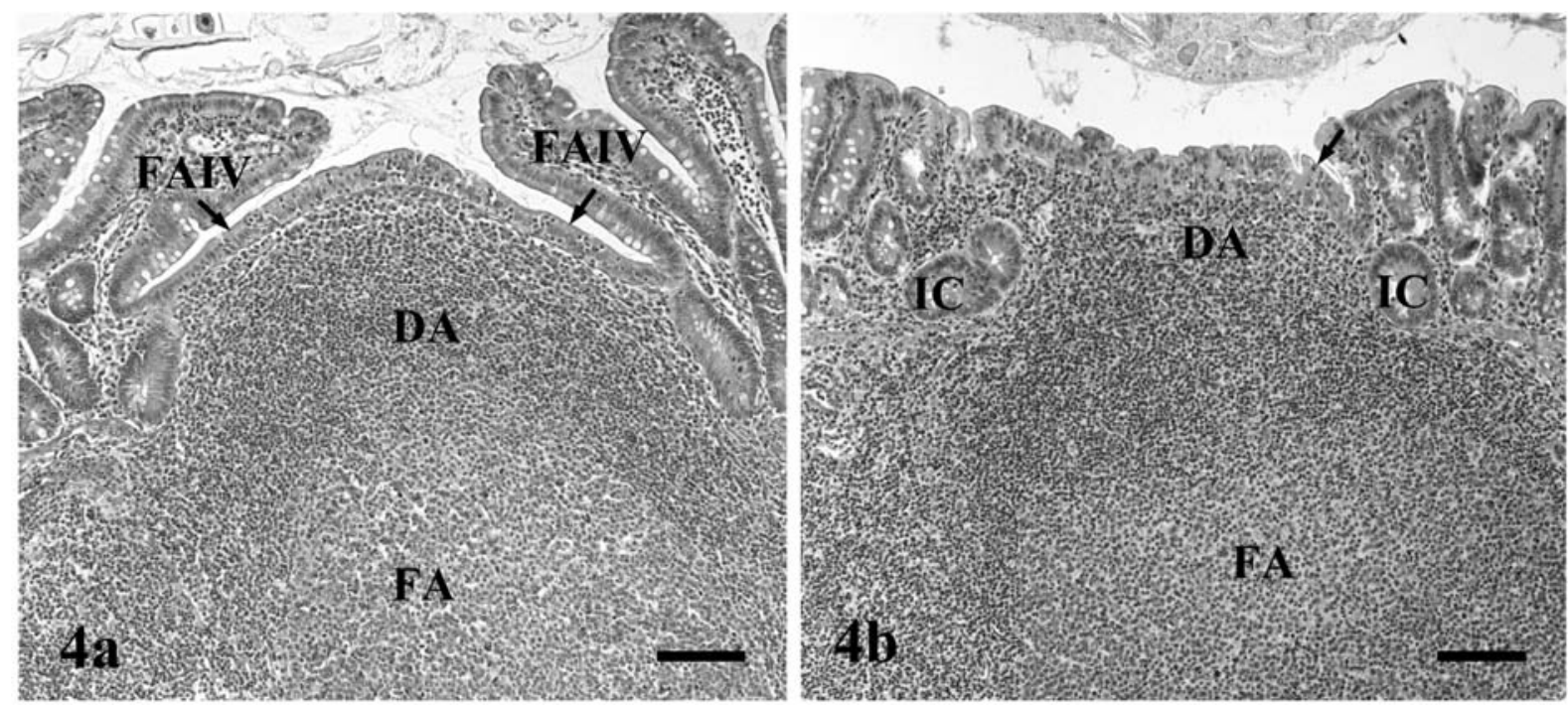

Fig. 4. a) A mucosal lymphatic follicle (LF) in rat ileum. The follicle-associated epithelium (arrows) and the dome area (DA) are incompletely covered by the follicle-associated intestinal villi (FAIV). The dome is slightly lower than the neighboring intestinal villi. b) The mucosal LF in the cecum. The FAE (arrow) and DA are located in the level of the intestinal crypts (IC). FA, follicular area. $\mathrm{Bar}=100 \mu \mathrm{m}$.
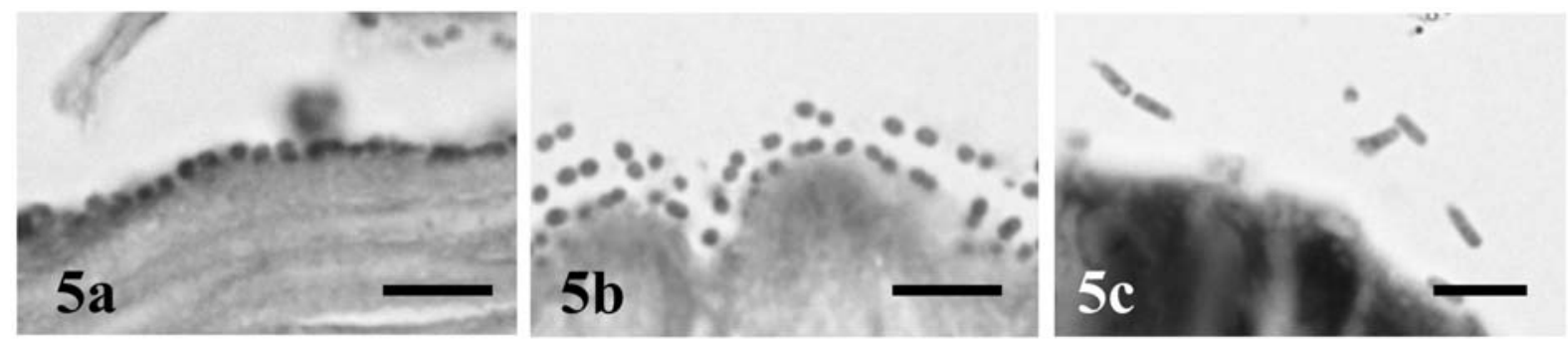

Fig. 5. The several types of indigenous bacteria in the alimentary tract. a) Type C3 bacteria are visible on the lingual epithelium. Type B1 (b) and type B7 (c) bacteria are visible on the villous epithelium of jejunum and ileum, respectively. Bar $=5 \mu \mathrm{m}$.

epithelium of the most luminal mucosa, whereas almost all of the indigenous bacteria in the intestinal crypts were suspended in the mucus (Fig. 6d, 10).

Type B13 and B15 bacteria resided from the most luminal mucosa to the intestinal crypt bottoms in the cecum and the proximal $30 \%$ of the colon. These bacteria also adhered to the FAE of the neighboring mucosal LF. In the distal $70 \%$ of the colon, type B2, B7, B11, B13 and B15 bacteria resided only on the most luminal mucosa, but never adhered to the FAE of the neighboring mucosal LF.

\section{DISCUSSION}

In mice and rats, the proliferative sites of intestinal epithelial cells are the middle portions of intestinal crypts in the small intestine $[1,6]$, and the lower half of the intestinal crypts in the large intestine [5, 25]. As newly generated epithelial cells migrate, apoptosis is induced and they are finally shed from the apical portions of the intestinal villi $[27,28]$. This migration process of epithelial cells is assumed to be the same in the large intestine. The apices of both the intestinal villi and the dome of mucosal LF are also the sites where indigenous bacteria were repeatedly adhered to the apoptotic epithelial cells and eliminated by the physical and chemical actions of the apoptotic ones [17]. In the present study, the portions around the apices of intestinal villi in the small intestine and the most luminal mucosa in the large intestine, which are also the shedding sites of the effete epithelial cells at the late apoptotic stage, are the constant adhering sites of indigenous bacteria. Therefore, the constant colonization of indigenous bacteria might be principally maintained by the delicate balance of the elimination rate of indigenous bacteria and the bacterial proliferation rate.

In the stratified squamous epithelium, the epithelial cells proliferate in the basal layer, undergo the process of apoptosis as they head toward the corneal layer, and eventually shed off $[13,14,29]$. In the human esophagus, Fas-FasL-mediated apoptosis contributes to the epithelial turnover [2]. The most superficial layer of the epithelium of 

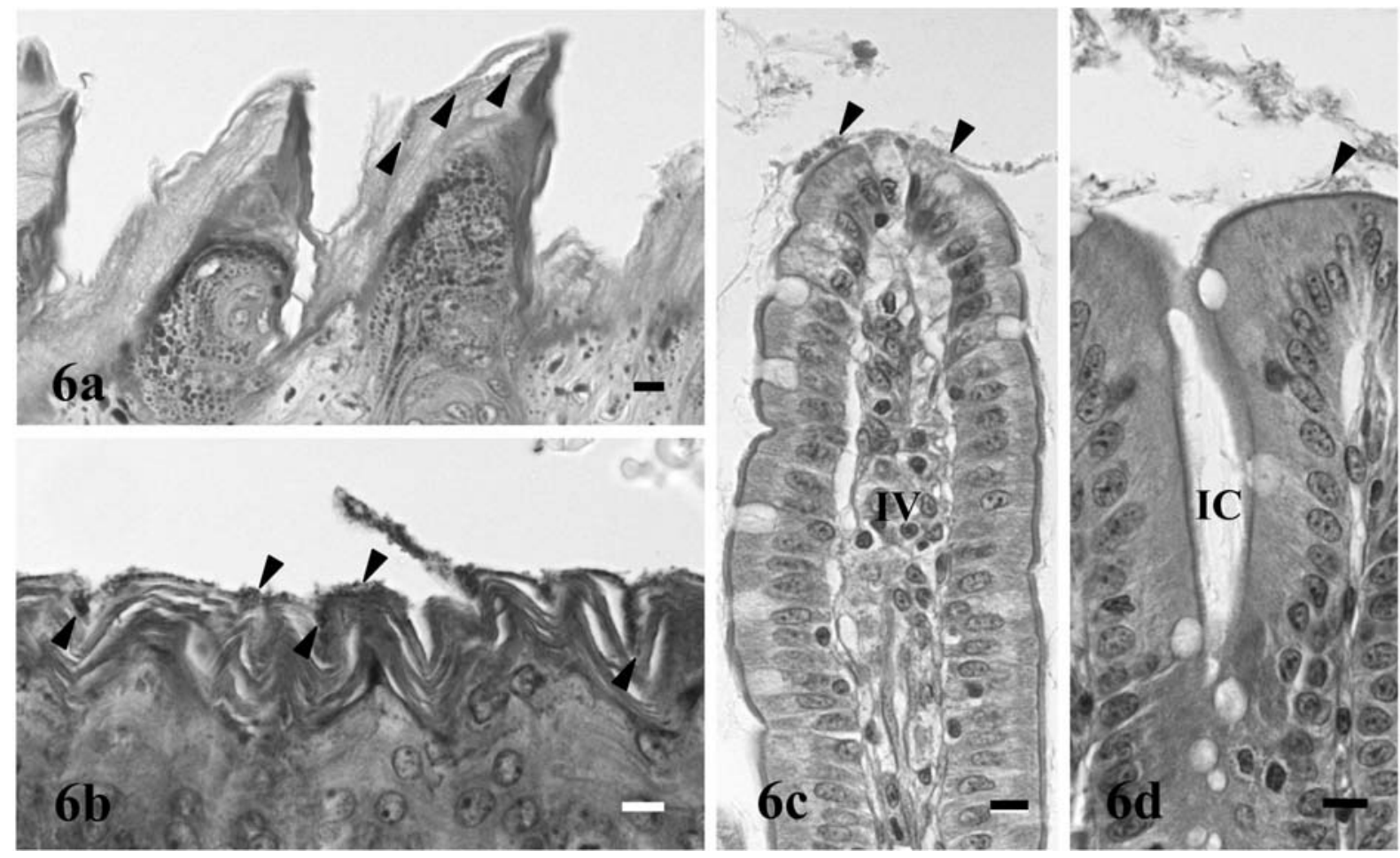

Fig. 6. Many minute bacteria (arrowheads) are visible on the surface and in the corneal layer of filiform papilla (a) and the nonglandular part of stomach (b) in rat. Minute bacteria (arrowheads) adhere to the epithelium of the apical portion of intestinal villi (IV) in the ileum (c) and the most luminal mucosa in the cecum (d). IC, intestinal crypt. Bar $=10 \mu \mathrm{m}$.

Table 1. Morphological typing of the indigenous bacteria observed in this study

\begin{tabular}{llll}
\hline Type & Size $(\mu \mathrm{m})$ & Form & Stainability of cytoplasm \\
\hline B 1 & $0.8 \times 1.0$ & coccobacillus & wB-C and wB-E \\
B 2 & $0.5 \times 1.2$ & bacillus & wB \\
B 3 & $1.0 \times 1.2$ & coccobacillus & wB \\
B 4 & $0.8 \times 1.5$ & bacillus & B \\
B 5 & $1.0 \times 1.5$ & bacillus & Ch-C and wB-R \\
B 6 & $1.0 \times 2.0$ & bacillus & B \\
B 7 & $0.8 \times 2.1$ & bacillus & B \\
B 8 & $1.0 \times 2.5$ & bacillus & wB-C and wB-E \\
B 9 & $0.9 \times 3.0$ & bacillus & B \\
B10 & $1.0 \times 3.5$ & bacillus & B \\
B11 & $1.0 \times 4.0$ & bacillus & B \\
B12 & $1.5 \times 4.5$ & bacillus & wB-C and wB-E \\
B13 & $1.0 \times 5.0$ & bacillus & Ch-C and wB-R \\
B14 & $1.0 \times 5.0$ & bacillus & B \\
B15 & $1.2 \times 11.0$ & bacillus & Ch-C and wB-R \\
C 1 & $0.3 \times 0.3$ & coccus & B \\
C 2 & $0.8 \times 0.8$ & coccus & wB \\
C 3 & $1.2 \times 1.2$ & coccus & B \\
\hline
\end{tabular}

B, basophilic; wB, weakly basophilic; wB-C, weakly basophilic center; wB-E, weakly basophilic extremity; wB-R, weakly basophilic rim; Ch-C, chromophobe center.

the tongue, esophagus and nonglandular portion of stomach is the corneal layer, which is an important site of the exfoliation of effete epithelial cells. In the mouse oral cavity, the corneal layer of the mucosal epithelium replaces itself in 2-4 hr, and this replacement is thought to be the most effective mucosal defense [20]. In the present study, the corneal layer of the tongue, esophagus, and nonglandular part of stomach was a consistent adhesion site of indigenous bacteria. In addition, the epithelial cells in the glandular part of the stomach are generated from stem cells from the basal portions of gastric pits to the necks of the gastric glands, and migrate bidirectionally $[18,19]$. In the present study, the bacterial adhesion sites in the glandular part are the most luminal mucosa where the effete epithelial cells accumulate. These findings suggest that the most luminal mucosa is a consistent adhesion site of indigenous bacteria through the entire alimentary tract, and that bacterial colonies of the most luminal mucosa might be the origin of indigenous bacteria in both the chyme and the gaps of the mucosa in the alimentary tract.

Almost all of the domes of LF were incompletely covered with adjacent mucosa in the rat and human Peyer's patches and the rabbit appendix [7, 22, 23]. We also confirmed that the mucosal LF were incompletely covered with follicleassociated intestinal villi and intestinal crypts in the rat small and large intestines respectively. In the small intestine, the FAE of the domes, whose heights were slightly lower than those of the intestinal villi, was situated at a level outside of the intestinal crypts, whereas the FAE were embedded in the intestinal crypts in the large intestine. In 


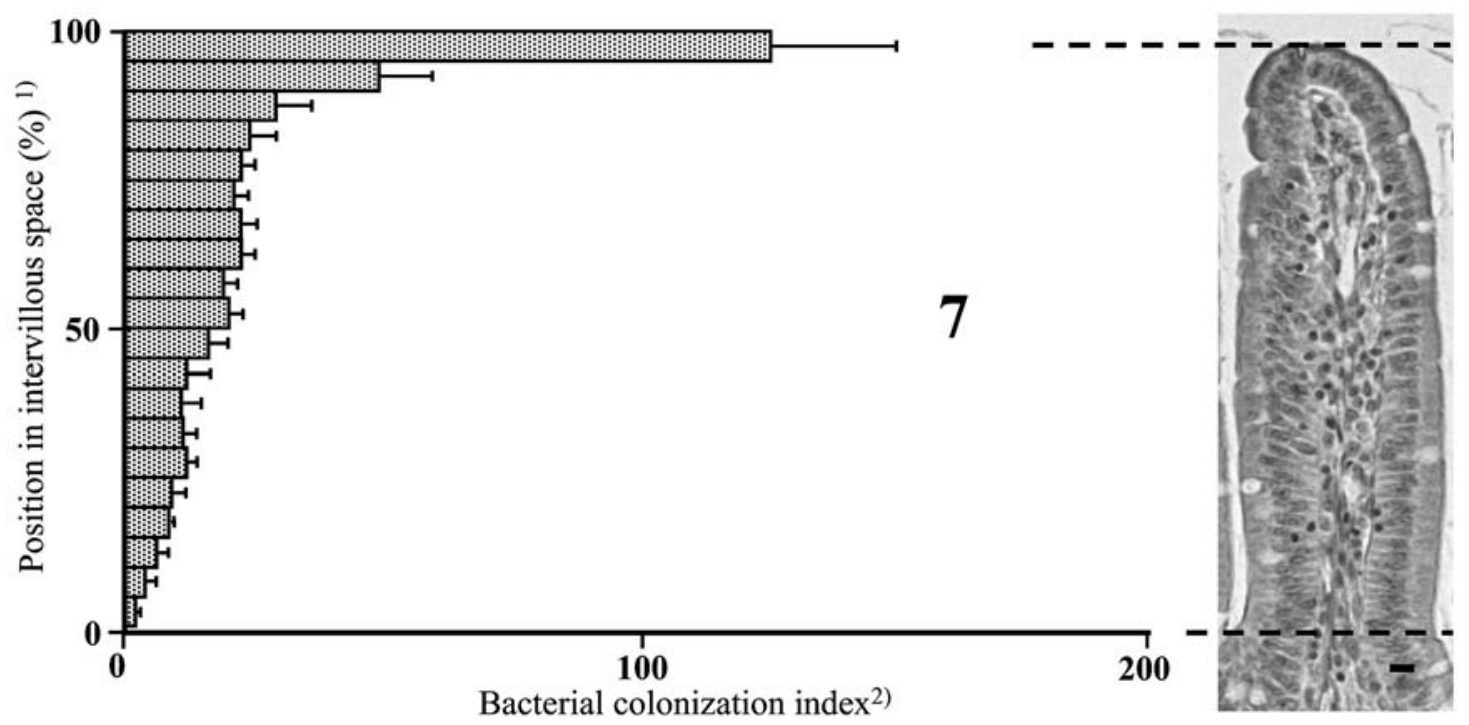

Fig. 7. Distribution of the indigenous bacteria in the intervillous spaces throughout small intestine in rat. 1) The length from the crypt orifice to the apex of the intestinal villus is represented as $100 \%$. Right micrograph is an intestinal villus whose length is consistent with the $100 \%$ in the left graph. 2) The mean number ( \pm SD) of points where a bacterial colony existed in each rectangular area with $1 \%$ of horizontal length times $5 \%$ of height of the intestinal villus.

cases in which the indigenous bacterial colonies expanded into the shallow intervillous spaces or did not expand at the most luminal mucosa in the large intestine, the same morphological type of indigenous bacterial colonies never adhered to the FAE of the neighboring mucosal LF. In contrast to this, in cases in which indigenous bacterial colonies expanded into the deep intervillous spaces in the small intestine or filled the lumina of the intestinal crypts in the large intestine, the same type of indigenous bacteria also adhered to the FAE of the neighboring mucosal LF. In addition, no indigenous bacteria invaded into the lumina of intestinal crypts in the small intestine, whereas indigenous bacteria colonized in the lumina of the intestinal crypts in the proximal large intestine. The uptake of bacteria by $\mathrm{M}$ cells is thought to contribute to the regulation of the expansion of indigenous bacterial colonies in the small intestine $[7,16]$. Therefore, the present morphological and histoplanimetrical data suggest that mucosal LF might monitor the development of bacterial colonies in the small area around the LF in the rat small and large intestines.

In the present study, the lumina of intestinal crypts were filled with indigenous bacteria from the cecum to proximal colon, whereas no indigenous bacteria colonized the intestinal crypts in the distal colon and rectum. In the cecum and proximal colon, fermentation results in the production of large amount of short-chain fatty acids and promotes rapid bacterial growth, whereas in the distal colon, the bacterial population is close to static [12]. Various defensive factors such as the kinetics of epithelial cells and the secretion of antimicrobial substances and natural antibodies have been hypothesized to be involved in maintaining constant numbers and balance of indigenous bacteria [8, 16, 17, 24]. Therefore, the present data suggest that the regulation mechanism with various defensive factors in the proximal colon might differ from that of the distal colon and rectum.

ACKNOWLEDGMENT. This work was financially supported in part by a Grant-in-Aid for Scientific Research (no. 19580339) from the Japan Society for the Promotion of Science.

\section{REFERENCES}

1. Appleton, D. R., Al-Dewachi, H. S., Morley, A. R., de Rodriguez, M. S., Sunter, J. P., Watson, A. J. and Wright, N. A. 1983. Autoradiographic investigations of cell proliferation in the small and large bowel of the mouse, and the jejunal response to some abnormal conditions. Acta Histochem. (Suppl.) 27: 185-194.

2. Bennet, M. W., O’Connell, J., O’Sullivan, G. C., Roche, D., Brady, C., Collins, J. K. and Shanahan, F. 1999. Fas ligand and Fas receptor are coexpressed in normal human esophageal epithelium: a potential mechanism of apoptotic epithelial turnover. Dis. Esophagus 12: 90-98.

3. Bourlioux, P., Koletzko, B., Guarner, F. and Braesco, V. 2003. The intestine and its microflora are partners for the protection of the host: Report on the Danone Symposium "The Intelligent Intestine”, held in Paris, June 14, 2002. Am. J. Clin. Nutr. 78: 675-683.

4. Byrne, B. M. and Dankert, J. 1979. Volatile fatty acids and aerobic flora in the gastrointestinal tract of mice under various conditions. Infect. Immun. 23: 559-563.

5. Chang, W. W. and Nadler, N. J. 1975. Renewal of the epithelium in the descending colon of the mouse. IV. Cell population kinetics of vacuolated-columnar and mucous cells. 

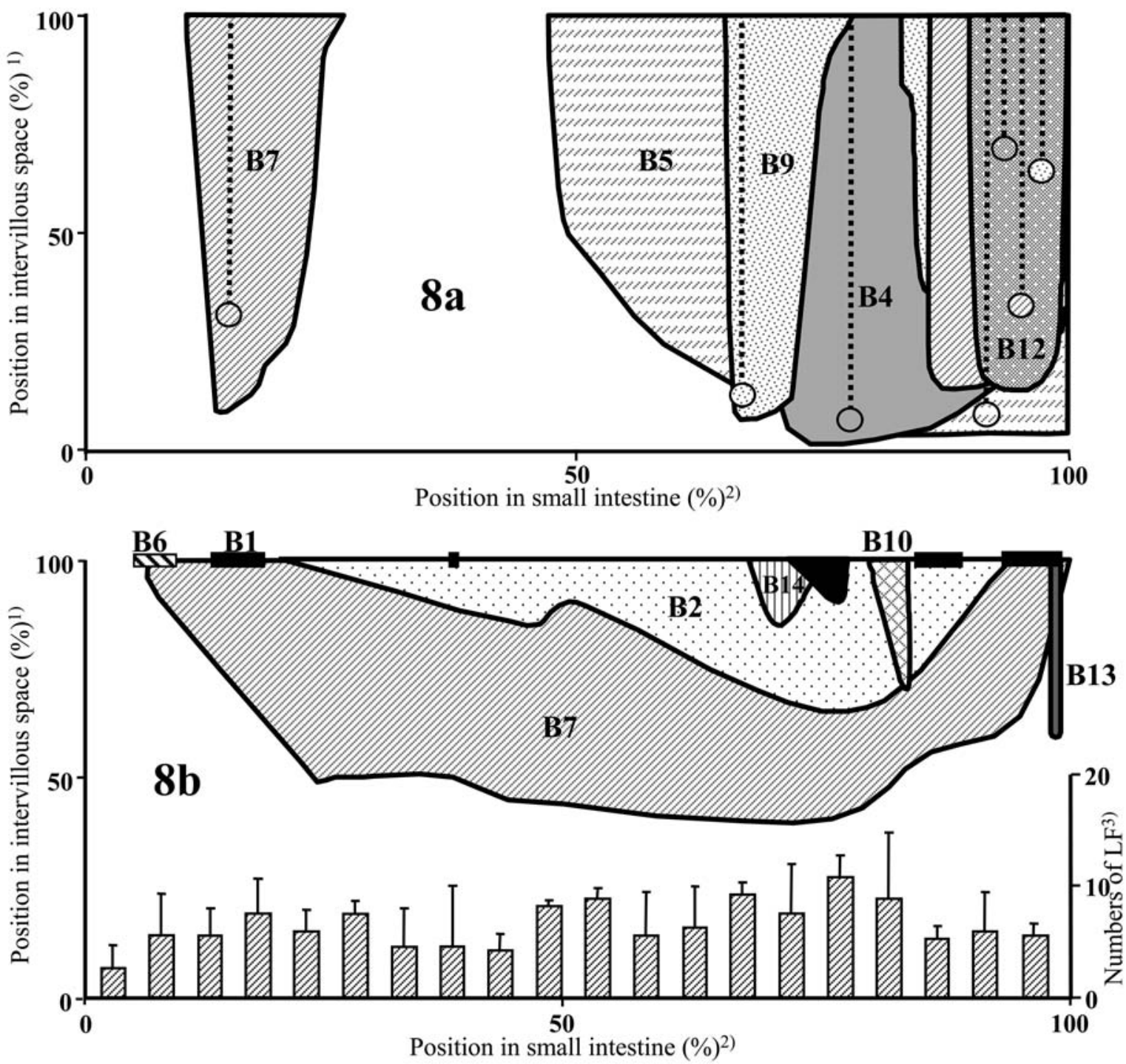

Fig. 8. The spatial relationship between the distribution of each typical bacterial colony and the situation of mucosal lymphatic follicle (LF). a) In cases in which bacterial colonies expand to the level of the basal portions of intestinal villi, the bacterial colonies located on the follicle-associated epithelium (FAE) of LF are represented as small circles. The painted pattern in the circle is same as that of the corresponding area of the bacterial colony. b) In cases in which bacterial colonies expand to the level of the apical or middle portions of intestinal villi, no bacterial colony is located on the FAE of LF. The lower graph represents the distribution of mucosal LF in rat small intestine. 1) The mean number $( \pm S D$ ) of the mucosal LF is represented in each $5 \%$ length. 2) The length from the pyloric opening to the ileal opening is represented as $100 \%$. 3) The mean number ( \pm SD) of total mucosal LF was represented in each $5 \%$ length.

Am. J. Anat. 144: 39-56.

6. Chen, W., Meinzer, H. P. and Sandblad, B. 1988. The growth and life of a monoclonal crypt. Cell Tissue Kinet. 21: 419-427.

7. Chin, K., Onishi, S., Yuji, M., Inamoto, T., Qi, W.-M, Warita, K., Yokoyama, T., Hoshi, N. and Kitagawa, H. 2006. Differentiation of epithelial cells to $\mathrm{M}$ cells in response to bacterial colonization on the follicle-associated epithelium of Peyer's patch in rat small intestine. J. Vet. Med. Sci. 68: 10231028.

8. Cole, A. M. and Ganz, T. 2005. Defensins and other antimicrobial peptides: Innate defense of mucosal surfaces. pp. 17-34. In: Colonization of Mucosal Surfaces (Nataro, J. P.,
Cohen, P., Mobley, H. T. and Weiser, J. eds.), ASM Press, Washington, D. C.

9. Cummings, J. H., Bingham, S. A., Heaton, K. W. and Eastwood, M. A. 1992. Fecal weight, colon cancer risk and dietary intake of non-starch polysaccharides (dietary fiber). Gastroenterology 103: 1783-1789.

10. Dickman, M. D., Chappelka, A. R. and Schaedler, R. W. 1976. The microbial ecology of the upper small bowel. Am. J. Gastroenterol. 65: 57-62.

11. Fagarasan, S., Muramatsu, M., Suzuki, K., Nagaoka, H., Hiai, H. and Honjo, T. 2002. Critical roles of activation-induced cytidine deaminase in the homeostasis of gut flora. Science 


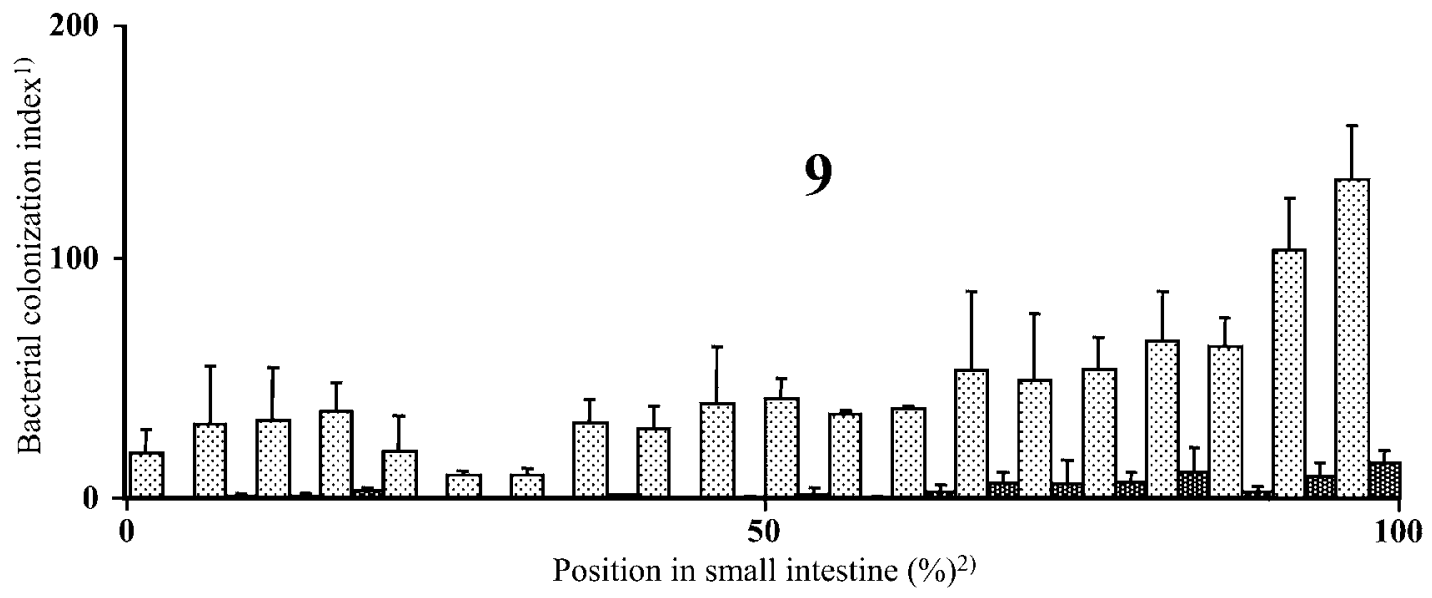

Fig. 9. The relationship between the total points of indigenous bacteria on the mucosa (light columns) and that on the FAE of mucosal lymphatic follicle (LF) (dark columns) throughout small intestine. 1) The mean number $( \pm$ SD) that the existence of bacterial colony is counted as 1 point in each square area with $1 \%$ of horizontal length times $5 \%$ of height of intestinal villus, is represented in each $5 \%$ horizontal length. 2) The length from the pyloric opening to the ileal opening is represented as $100 \%$.

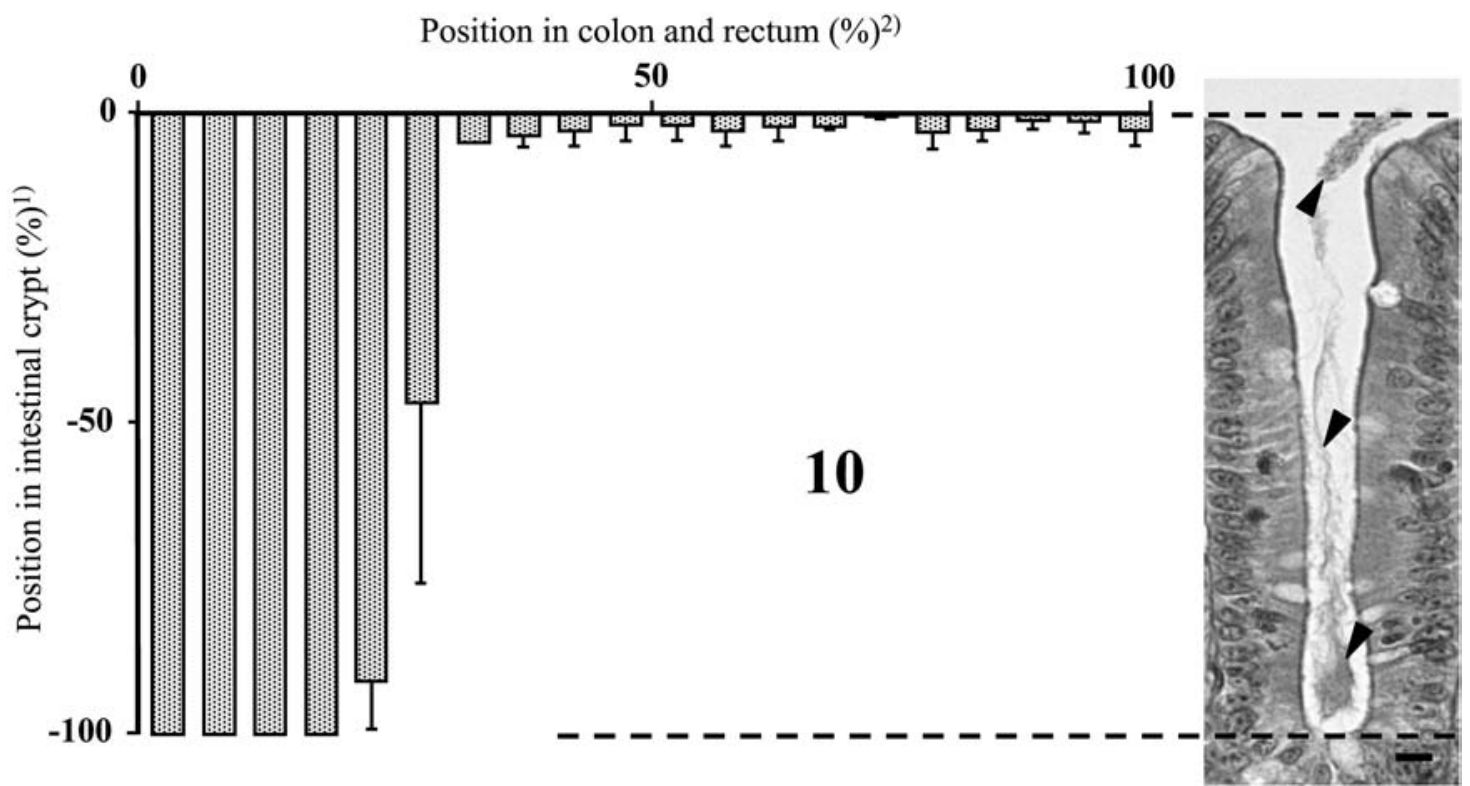

Fig. 10. Distribution of indigenous bacteria in the intestinal crypts of colon and rectum in rat. 1) The length from the crypt orifice to the bottom of crypt is represented as $100 \%$. The right photograph is an intestinal crypt whose length is consistent with the $100 \%$ in the left graph. Indigenous bacteria (arrowheads) are suspended in the mucus in the crypt lumen. 2) The full (100\%) length from the cecocolic orifice to the end of rectum is represented as $100 \%$. Each value represents a mean \pm SD.

298: $1424-1427$.

12. Guarner, F. and Malagelada, J. R. 2003. Gut flora in health and disease. Lancet 361: 512-519.

13. Haake, A. R. and Polakowska, R. R. 1993. Cell death by apoptosis in epidermal biology. J. Invest. Dermatol. 101: 107112.

14. Haake, A. R., Roublevskaia, I. and Cooklis, M. 1998. Apoptosis: a role in skin aging? J. Invest. Dermatol. Symp. Proc. 3: 28-35.
15. Hill, M. J. and Drasar, B. S. 1975. The normal colonic bacterial flora. Gut 16: 318-323.

16. Inamoto, T., Kawata, Y., Qi, W.-M., Yamamoto, K., Warita, K., Kawano, J., Yokoyama, T., Hoshi, N. and Kitagawa, H. 2008. Ultrastructural study on the epithelial responses against attachment of indigenous bacteria to epithelial membranes in Peyer's patches of rat small intestine. J. Vet. Med. Sci. 70: 235241.

17. Inamoto, T., Namba, M., Qi, W.-M., Yamamoto, K., Yokoo, 
Y., Miyata, H., Kawano, J., Yokoyama, T., Hoshi, N. and Kitagawa, H. 2008. An immunohistochemical detection of actin and myosin in the indigenous bacteria-adhering sites of microvillous columnar epithelial cells in Peyer's patches in the rat jejunoileum. J. Vet. Med. Sci. 70: 1153-1158.

18. Karam, S. M. 1995. New insights into the stem cells and the precursors of the gastric epithelium. Nutrition 11: Suppl. 607613.

19. Karam, S. M. and Leblond, C. P. 1993. Identification of proliferative cell types and pinpointing of the stem cell. In dynamics of epithelial cells in the corpus of the mouse stomach. Anat. Rec. 236: 259-279.

20. Kvidera, A. and Mackenzie, I. C. 1994. Rates of clearance of the epithelial surfaces of mouse oral mucosa and skin. Epith. Cell Biol. 3: 175-180.

21. Luckey, T. D. 1972. Introduction to intestinal microecology. Am. J. Clin. Nutr. 25: 1292-1294.

22. Marchetti, M., Sirard, J. C., Sansonetti, P., Pringault, E. and Kerneis, S. 2004. Interaction of pathogenic bacteria with rabbit appendix M cells: bacterial motility is a key feature in vivo. Microbes Infect. 6: 521-528.

23. Owen, R. L. and Jones, A. L. 1974. Epithelial cell specialization within human Peyer's patches: an ultrastructural study of intestinal lymphatic follicles. Gastroenterology $\mathbf{6 6}$ : 189-203.
24. Pearson, J. P. and Brownlee, I. A. 2005. Structure and function of mucosal surfaces. pp. 3-16. In: Colonization of Mucosal Surfaces (Nataro, J. P., Cohen, P., Mobley, H. T. and Weiser, J. eds.), ASM Press, Washington, D.C.

25. Pozharisski, K. M., Klimashevski, V. F. and Gushchin, V. A. 1980. Study of kinetics of epithelial cell populations in normal tissues of the rat's intestines and in carcinogenesis. I. A comparison of enterocyte population kinetics in different segments of the small intestine and colon. Exp. Pathol. 18: 387-406.

26. Savage, D. C. 1977. Microbial ecology of the gastrointestinal tract. Annu. Rev. Microbiol. 31: 107-133.

27. Shibahara, T., Sato, N., Waguri, S., Iwanaga, T., Nakahara, A., Fukutomi, H. and Uchiyama, Y. 1995. The fate of effete epithelial cells at the villus tips of the human small intestine. Arch. Histol. Cytol. 58: 205-219.

28. Takeuchi, T., Kitagawa, H., Imagawa, T. and Uehara, M. 1999. Apoptosis of villous epithelial cells and follicle-associated epithelial cells in chicken cecum. J. Vet. Med. Sci. 61: 149154.

29. Teraki, Y. and Shiohara, T. 1999. Apoptosis and the skin. Eur. J. Dermatol. 9: 413-426.

30. $\mathrm{Xu}$, J. and Gordon, J.I. 2003. Inaugural article: Honor thy symbionts. Proc. Natl. Acad. Sci. U. S. A. 100: 10452-10459. 